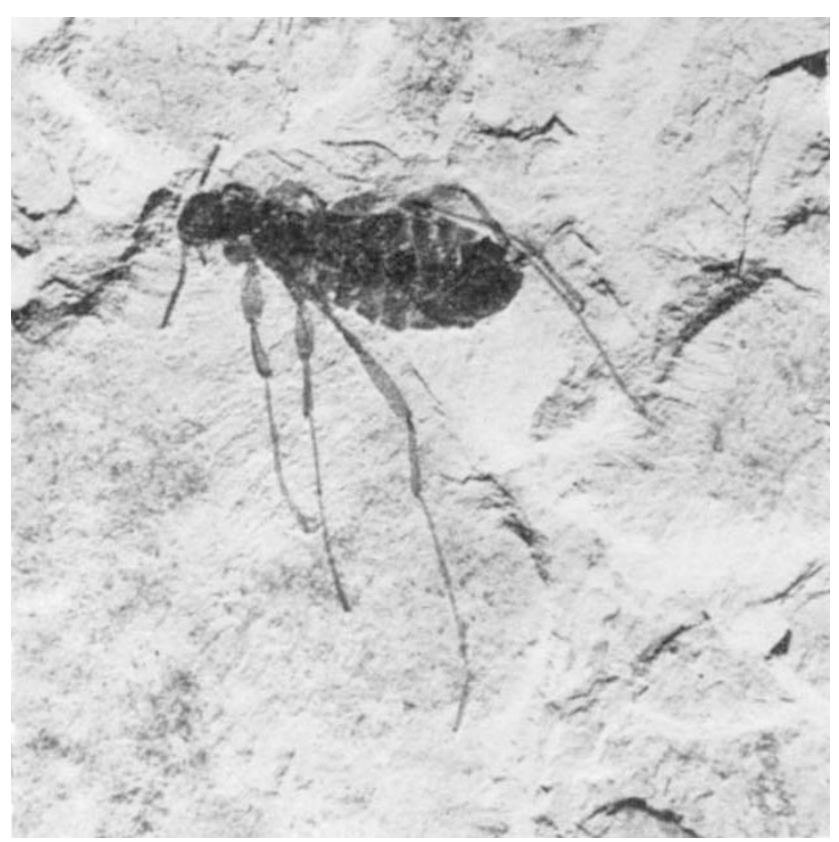

Fig. 1. One of the Koonwarra fleas.

bristles: the hind femur is not enlarged for jumping. The structure of the legs suggests that this insect lived on a sparsely haired (furred) animal and that it clung to the outer portions of the hairs rather than burrowed between the hairs. The specimen, with a body length of $7 \mathrm{~mm}$, is large as compared with most modern fleas, especially as it is a male: male fleas are distinctly smaller than females. Females of some modern fleas, however, are of this order of size. The nematocerous-type antennae tend to support the more usually accepted conclusion that the fleas evolved from a nematocerous-type ancestor.

The presence of two very different types of fleas or flealike insects in the Lower Cretaceous, one of which is similar to modern fleas, indicates that the Siphonaptera must have had a long history before the Lower Cretaceous. The more primitive of the two species shows that loss of wings and development of a specialized copulatory mechanism occurred before reduction in nematocerous-like antennae resulted in their being recessed in grooves on the head, and before the development of combs on the head and thorax. The Siphonaptera must have arisen from a primitive nematocerous-like ancestor before specialization of the male terminalia resulted in structures similar to those of modern Nematocera. Undoubted Diptera are recorded from the Triassic. It seems probable that the Siphonaptera evolved from nematocerous Diptera in the Late Triassic or early Jurassic, at about the same time as the first warm blooded vertebrates.

Deductions concerning the ecological association of at least the more primitive of the two species with a furred animal, and not a bird, indicate that marsupials must. have been present in Australia at a very much earlier period than has hitherto been conceded, and this species thus sheds $n e w^{*}$ light on the probable centre of origin, and on the early dispersal of the marsupials as it affects the zoogengraphy of the southern continents.

EDgar F. RIEK

Commonwealth Scientific and Industrial Research

Organization,

Division of Entomology,

Canberra,

Australia.

Receired January 6; revised April 29, 1970.

1 Talent, J. A., Duncan, P. M., and Handby, P. L., Emu, 66, 81 (1966).

\section{Taxonomy and Cranial Capacity of Olduvai Hominid 7 (continued)}

Pilbeam rejects ${ }^{1}$ my recent estimate of cranial capacity for Homo africanus ${ }^{2}$. As I understand his comment, he disputes treatment of Olduvai hominid 7 with the South African gracile australopithecines as one statistical population because they may belong to separate subspecies.

The question of how many subspecies may exist within Homo africanus was never raised because it is not relevant. Given the possible time span of this taxon, and the nature of many hominid-bearing deposits, the only safe assumption would be that each specimen represents a distinct biological population. It is for precisely this reason that species are generally the smallest meaningful taxonomic unit for fossil material ${ }^{4}$. When cranial capacity is considered as a species parameter, the specimens representing the species make up the statistical universe. It seems to me that estimations of species parameters are best made if all of the specimens referred to the species are considered. Indeod, Pilbeam seems to contradict himself, supporting the inclusion of Olduvai hominid 7 in "africanus" on the basis of cranial capacity, in a paper" published the same month as the comment considered here ${ }^{1}$ (October 1969).

It may be added that the use of a $t$ test for small samplo sizes is mislcading. It is not unusual to find relatively high $t$ values for the large or small ends of a small sample. For instance, using the published data for Homo erectus ${ }^{2}$, the $t$ value calculated for the largest Homo erectus cranium (skull 10 from Choukoutien) is 2.93 ( 10 degrees of freedom). 'This indicates a probability of 0.98 that the largest Homo erectus cranium does not differ from the eleven other crania by chance alone. It does not place skull 10 in another species, let alone another genus.

In fact, this result does not even mean that skull 10 is necessarily representative of a scparate biological population. The parameters which characterize taxa, whether on subspecies, species or supraspecies levols, can only be derived from the distribution of the actual specimens ${ }^{8}$.

In sum, Pilbeam's criteria for drawing firm taxonomic conclusions have been met in the case of Olduvai hominid 7. 'There is no morphological evidence in either the dentition or the cranial capacity which justifies, or even suggests, the separation of this specimen from Homo africanus.

Department of Anthropology,

Mrthord H. WOLPOFF

Case Western Reserve University,

Cleveland.

Received December 5, 1969.

1 Pilbeam, D., Nature, 224, 386 (1969).

' Wolpoff, M. H., Nature,223, 182 (1969).

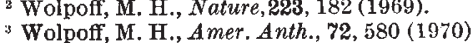

- Simpson, G. G. in Classification and Human Evolution (edit. W Washburn S. I.), 1 (Aldine, New York, 1963).

"Simons, E. L., Pilbeam, D., and Ettel, P. C., Science, 166, 258 (1969).

- Mayr, E., Principles of Systematir. Zoology (McGraw-Hill, New York, 1969).

\section{Early Hominids and Cranial Capacities (continued)}

I sHould like to make a few points arising from the previous letter'. Much of the debate centres around the problem of species in palaeontology; how to define these, and how to assign now specimens to their appropriate taxon". It is obvious that "the specimens representing the species make up the statistical universe". Tho point which Wolpoff ignores is the manner in which individual specimens are assigned to "species". In classifying fossils, duo attention must be paid to variation within and between infraspecific populations, as well as to possible variation due to time ${ }^{2}$. The most important issue to decide in the 